\title{
Theory-Assessment in the Historiography of Science
}

\author{
by JAMES W. MCALLISTER \\ I History and Norms of Rationality \\ 2 Varieties of Relativism \\ 3 Comprehension and Criticism \\ 4 The Roles of Evaluation
}

This paper argues that evaluation of the truth and rationality of past scientific theories is both possible and profitable. The motivation for this enterprise is traced to recent discussions by I. Lakatos, L. Laudan and others on the import of history for the philosophy of science; several objections to it are considered and T. S. Kuhn is found to advance the most substantive. An argument for establishing judgements of rationality and truth in the face of scientific revolutions is presented; finally evidence is offered for the value of such assessments to historiography and to debates on scientific progress.

\section{HISTORY AND NORMS OF RATIONALITY}

The historian of science A. Koyré revelled in exclaiming of past thinkers 'And he was right!'. This paper ${ }^{1}$ will argue that evaluations of the truth and rationality of past science form a proper part of the historian's task. Evaluations of past truth consist in the attribution of our own truth-values to previous scientific assertions, whilst evaluations of rationality mean the tracing of any divergences between past inferences and those that we would regard legitimate under the same premises. To establish our conclusion it will be necessary to discuss the philosophical motivations for such assessments, some arguments purporting to show their impossibility or undesirability, and the roles of evaluation in historiography. Theoryassessment will be found much more valuable for our understanding of past science than merely going through history picking off wrong answers.

The motivation for this enterprise springs from the recent reaction to a previously standard view according to which history and philosophy were separate if complementary ways of studying science. The historian on this view was dealing with facts and data, seeking to arrange them into a coherent

Received 7 May ${ }_{198}$ 'An earlier version of this paper was presented at a Philosophy of Science seminar at the Inter-
University Centre of Postgraduate Studies in Dubrovnik in April 1985 . I wish to thank the
participants for constructive criticism and Dr Nicholas Jardine of the University of Cambridge
for help and advice. 


\section{I6 James W. McAllister}

and convincing tale about how scientific ideas have evolved; philosophy of science was by contrast perceived as a normative, evaluational and largely $a$ priori investigation of how science ought to proceed. This view has been criticized by many recent thinkers including T. S. Kuhn, I. Lakatos and L. Laudan. Whilst granting that the aim of philosophical inquiry is the generation of a set of norms, including some to direct the evaluation of theories, these critics have pointed out that any philosophical theory of science which failed substantially to square with the history of science would be deemed unacceptable: we should reject for instance an account of theorychange which interpreted a substantial part of the history of science as irrational. This criticism implies that history has an evidential role for philosophy of science.

But this last point presupposes acceptance of a thesis equally foreign to the standard view: that evaluations of the truth and rationality of past science are potentially well-founded. If we did not believe ourselves capable of making assessments of past science, we would be unable to gauge the standard of rationality of episodes of actual history and therefore to judge the extent of the agreement between those episodes and models of rationality embodying our philosophical norms. The cited critics of the standard view have accordingly each developed ways for evaluating past science in order to ascertain the degree of concordance between their methodological rules and actual history. This is the aim of Lakatos' theory of rational reconstructions, which purports 'to explain how the historiography of science should learn from the philosophy of science' ([1971], p. 91; emphasis in original). In order to erect a rational reconstruction of the historical record one tells history as it ought to have happened; the actual beliefs of the historical agents who star in the story are often ignored or deliberately distorted. Sometimes not just the truth-values of the agents' beliefs but also their canons of rationality are modified: in discussing the hypotheses on chemical composition of the nineteenth-century physician William Prout, for instance, Lakatos urges the historian to ignore one of Prout's methodological tenets about the experimental grounding of theories. Once an episode has been thus recast, Lakatos proceeds to appraise its rationality. Yet whatever the verdict, the historical episode itself and the beliefs that figure in it remain unevaluated as well as unexplained.

Aware of the inadequacies of Lakatos' view, Laudan has proposed an intuitionist base upon which to provide history with an evidential role. Laudan believes he identifies within the history of science a number of 'preanalytic intuitions' of rationality, constituting 'a subclass of cases of theoryacceptance and theory-rejection about which most scientifically educated persons have strong (and similar) normative intuitions' ([1977], p. 160). This set contains among others the intuition that it was rational by 1890 to reject the view that heat was a fluid, or that it was irrational after 1830 to accept the biblical chronology as a literal account of Earth history. "The test of any putative model of rational choice is whether it can explicate the 
rationality assumed to be inherent in these developments' (ibid., p. I6r; emphasized in the original).

This construal of the evidential relation between history and methodology meets a number of difficulties; ${ }^{1}$ one of interest here concerns Laudan's account of how to make evaluative judgements in the historiography of science, and particularly his assumption that it is possible and uncontroversial to place confidence in pre-analytic intuitions about scientific rationality. The term 'intuition' is often a euphemism for common belief engendered by prolonged exposure or persuasion, a highly insecure basis upon which to rest our conception of scientific rationality. Under further cogitation, to have an intuition is to possess immediate knowledge of a concept without being able to define it; thus to present a certain historical episode as intuitively rational is to claim that it is rational without being capable of explicating why it is so or what form its rationality takes. This assertion would be historiographically insufficient because by definition unsupportable by evidence. So even in the more respectable sense of the term 'intuition', Laudan is gravely oversimplifying the task of the historian by denying any problematic feature to the interpretation of key episodes in the history of science. In view of Laudan's praiseworthy emphasis on the importance of history to philosophers of science, it is disappointing to find a similar misrepresentation of historiographic analysis.

The problem which Lakatos and Laudan are here failing to despatch is most clearly revealed by the aid of the familiar distinction between two senses of the term 'history of science', one denoting the actual past development of science and the other the descriptive and explanatory accounts composed about that development. Authors like Lakatos and Laudan, concerned to establish an evidential relationship between history and philosophy, focus upon the import for methodology of the actual past development of science; but since that development can be accessed only through the writings of historians, and since for an evidential relation to be established we require evaluations of past science, the problem thereby raised is that of determining whether normative elements from the philosophy of science are able within accounts of historical episodes to assess the truth and rationality of past science.

It is universally acknowledged that philosophical beliefs about science already influence the historian's selection and treatment of his subjectmatter: scholars as different as Koyré and Kuhn will give radically divergent accounts of the same episodes. But a further level at which philosophical judgements enter the written history of science is that of the epistemic assessment of past theories. Whereas the former normative influence is a pervasive conditioning which the individual historian may find hard to recognize explicitly in himself, the latter is generally a conscious use of a historiographic tool. As discussed in the next section, some currents of

${ }^{1}$ Some of these difficulties are discussed in Brown [1 980$]$, pp. 238-40, on which I have drawn. 


\section{Fames $W$. McAllister}

thought have seen in this deliberate intrusion of modern methodological norms into past science a violence against historicism which must be shunned.

\section{VARIETIES OF RELATIVISM}

Among the Egyptians and Arabians, the Paracelsians, and some other moderns, chemistry was very phantastic, unintelligible, and delusive. [. . .] The Royal Society have refined it from its dross, and made it honest, sober and intelligible [. . .].

Joseph Glanvill ([1668], p. 12) believed it eminently natural to formulate normative evaluations of past science, and his confident expectation is still shared by some today. It is noted that one of the primary aims of the written history of science is to explain why certain experiments, theories and research traditions were accepted, rejected or modified: many such explanations will involve normative assessments. The query 'Why did Newton reject Descartes' vortex-theory of planetary motion?' will elicit the response 'Because Newton judged the vortex-theory grossly incompatible with data about the positions and velocities of the planets'. The inquiry then arises, 'Was Newton correct in his criticism of the Cartesian theory, and why did he believe that a theory incompatible with data was to be rejected?', striving to establish the truth-value of Newton's beliefs and the standard of his rationality. We should be better informed on this episode if we were able to conclude e.g. that Newton had been justified in his dissatisfaction with Descartes' theory, or that he held a non-rational opinion of why theories at odds with data should be rejected; an unwillingness to refer to normative judgements would deprive us of this knowledge. Indeed even to conceive of a history of science one has to decide what counts as science and this arguably requires the introduction of evaluative norms.

Despite this expectation, strands in recent philosophy of science have tended to doubt the desirability and at times the very possibility of formulating such judgements. Similar currents of thought may in this context fittingly be termed varieties of relativism since they hold that past beliefs can be examined only in relation to historical background, thus abandoning substantive portions of the quest for commensuration. Five such stances will here be considered: historiographic conventionalism, externalism, philosophical nonalignment, hypothetico-deductivism and the Kuhnian school. ${ }^{1}$

I. The historiography of science has recently witnessed a reaction against the complacency that $H$. Butterfield has called 'Whiggish' ([193I], esp. pp. 9-31) and J. Agassi 'inductivist' ([1962], e.g. pp. I-3). This consists in the assumption that the present state of science is the ideal towards which have striven all previous beliefs, practices and institutions and is in this sense the paradigm of achievement. The inductivist historian thus inclines in the light

\footnotetext{
${ }^{1}$ The following survey is partially inspired by Hesse [1973], pp. 128-31.
} 
of contemporary knowledge to view all outdated theories as trivially false if not ridiculous and the past as an epic: Butterfield saw as an instance of this misrepresentation

the tendency in many historians to write on the side of Protestants and Whigs, to praise revolutions provided they have been successful, to emphasize certain principles of progress in the past and to produce a story which is the ratification if not the glorification of the present. ([193r], p. v)

Post hoc ergo melius hoc: in his opposition to this slogan Butterfield has been joined by S. G. Brush, a critic of those historians who

judge every scientist by the extent of his contribution toward the establishment of modern theories. Such an interpretation looks at the past in terms of present ideas and values, rather than trying to understand the complete context of problems and preconceptions with which the earlier scientist himself had to work. ([1974], p. I 169 )

In the face of such attacks, inductivist historiography has gradually been abandoned and efforts have by reaction been redirected towards the empathetic immersion of the historian in the complex of beliefs within which operated the scientists of interest. This approach, dubbed by Agassi 'conventionalism', has been characterized by mistrust for present-day judgements of past science, viewed as a manifestation of biased hindsight. The watchword has therefore been passed for historians to abstain from appraisals of past truth and rationality.

2. The issue of epistemic evaluation of scientific ideas has been sidestepped by the increasing injection into history of science of categories of psychology and sociology under the general name of 'externalist history'. Rationalists believe that internal factors are capable of explaining most of the past developments of science, and that external factors are to be invoked only when the rationalist model falters. Rational change is by them assumed to be the norm: only deviations from it are to be explained by reference to perturbing influences. Laudan voiced this opinion clearly:

When a thinker does what it is rational to do, we need inquire no further into the causes of his action; whereas, when he does what is in fact irrational-even if he believes it to be rational-we require some further explanation. ([1977], p. 188-9; emphasis in original)

By contrast adherents to the so-called strong programme in the sociology of science attack the very notion of the rational explanation of scientific change. Whereas the rationalist programme hinges on a differential assessment of belief, transmitting to the sociologist all and only those episodes regarded as unjustified, proponents of the strong programme like B. Barnes claim that all transitions should be attributed the same form of explanation whether or not we regard them as rational. On this view, to make our explanations of episodes of the history of science depend upon our present judgements about the form of rational decisions would be to project our beliefs illegitimately. Rather, Barnes writes, 'our present theories should stand 
symmetrically with earlier scientific theories' ([1977], p. 23). As a consequence of this principle of symmetry, all transitions and not merely socalled irrational ones are to be explained by reference to external factors, including such diverse influences as the standards of education of a society, unconscious psychological motivations and the metaphysical commitments of an age. There is no criterion isolating putative episodes in science wholly susceptible of internal explanation. This amounts to a denial of the specificity of internal history and of the utility in this context of theoryassessment: there is no need to evaluate the rationality of past actions before deciding on what form of explanation to advance for them. The formulation of historical explanations occurs with rationalist eyes shut.

3. Current philosophy has notoriously failed to provide a universally accepted account of scientific method. The contrary proliferation of models of rationality has undermined confidence among historians that normative evaluations of past science would not be irremediably tied to the fate of the pronouncements of individual philosophies which might rapidly lose favour among the community. Instantiations of this risk have been perceived in some accounts of historical episodes too heavily dependent upon idiosyncracies of polemic philosophy. Answering in the negative the query 'Should philosophers be allowed to write history?', L. P. Williams ([1975], p. 252) has charged philosophers with exploiting history to substantiate their own views on scientific method. Hypothetico-deductivism and the methodology of research programmes have appeared recently to spawn a particularly large number of partisan case-histories: J. T. Clark [1959], incisively criticized by even fellow-deductivist E. Nagel [1959], allows himself the free assumption of the postulates of the former to evaluate the actions of the protagonists of several past episodes, whilst C. Howson [ 1976 ] has assembled a number of histories incorporating the conceptual furniture of the latter. Anxious to compose accounts of longer life and wider appeal, most mainstream historians have shied from such close embrace of philosophical theses. Consequently the ideal has been envisaged of purely descriptive histories which refrain from evaluations grounded of necessity in philosophical doctrines.

4. Hypothetico-deductivism, indicted above of inducing naive history, has simultaneously tended to restrict the scope of evaluations of past rationality by its sharp demarcation of the context of justification from that of discovery. According to this distinction, originally introduced by logical positivism, justification is an eminently public affair, governed by rules and thus transparent to critical scrutiny, whereas discovery is of only private concern, neither subject to precepts nor susceptible of rational reconstruction. Since all paths leading to discovery are characterized by neopositivism as alogical, important parts of the historical record are withheld from epistemic evaluation.

5. Assessment of past theories is considered downright impossible by philosophies of science placing emphasis on deep discontinuities of ratio- 
nality or 'revolutions'. Such views have been advanced since the r 930 s when G. Bachelard wrote of ruptures épistémologiques ([1934], e.g. p. 176) and L. Fleck of the alternation of scientific Denkstile ([1935], esp. pp. 125-45), but their leading advocate today is of course Kuhn who explicitly invokes an analogy between scientific and political revolutions: in times of 'normal science' there is widespread agreement within the inquiring community on what constitutes solutions to the problems in hand, but in revolution scientists do not agree even on the principles that should govern the choice between paradigms. Theories embedded in rival paradigms simply cannot be compared since there are no theory-neutral principles relative to which this comparison could be carried out:

The normal-scientific tradition that emerges from a scientific revolution is not only incompatible but often actually incommensurable with that which has gone before. (Kuhn [1962], p. 103)

This is due to changes in both the meanings of the terms used by the scientists and the standards governing theory-preference: the former are claimed to preclude assessments of truth and the latter to impede evaluations of rationality. A typical example of meaning variance is constituted for Kuhn by Newtonian and Einsteinian mechanics, the terms of which are implicitly defined in each by reference to theory. There is thus no guaranteed stability of meaning for terms that figure in scientific theories: failure of translation occurs and gauging the truth or falsity of past propositions is problematic. This worry has been further pursued by $W$. V. Quine ([ 1 960], ch. 2) who argued that there can never be a unique translation of a sentence of one language into one of a second because the empirical evidence for one scheme of translation could always be reinterpreted in favour of another. Quine used this thesis, of the 'indeterminacy of radical translation', to cast doubt on whether there is a fact of the matter about what a sentence means, and hence on whether one sentence can ever 'mean the same' as another. Worse, even if we assumed invariance of meaning we would according to Kuhn find that in revolutions there are changes in the evaluative standards applied to theories. Kuhn speaks of paradigm-shifts bringing about 'changes in the standards governing permissible problems, concepts and explanations' ([1962], p. 106), citing as an example the late seventeenth-century transition from the visualization of gravity as susceptible of mechanistic explanation to its conception as a primary attribute of mass and hence not further explicable. Moreover, even if we arbitrarily fixed standards of explanation that cut across revolutionary divides, we would find it no less impossible to choose between alternative paradigms: the measure of the achievement of a paradigm is according to Kuhn the number of problems it has solved, but this cannot be taken as a comparative standard since each paradigm will in general solve a different subset of the problems within its scope and it is even in principle impossible to adjudicate between different sets of solved questions weighted in accordance with 


\section{Fames $W$. McAllister}

differing criteria. These difficulties appear to render impossible the task of identifying paradigm-neutral canons by which to evaluate the rationality of past science and, viewed in conjunction with meaning-drift hampering assessments of truth as outlined above, pose a severe threat to the entirety of our enterprise.

To be sure, Kuhn has withdrawn from his earlier more extreme position to allow the possibility of partial communication between the proponents of alternative paradigms and has offered a list of good-making characteristics of theories for which he expects there will be consensus across paradigms. The list includes the requirements of accuracy, consistency, breadth of scope, simplicity and fruitfulness ([1977], pp. 321-2). Even so Kuhn is far indeed from the positions of the rationalist, for he suggests that in the competition among paradigms for the support of scientists these factors are intended to play not evidential but persuasive roles. The normative force of the requirements cannot be justified on any account of scientific method but derives rather from their common acceptance in the community of peers. So whilst a new paradigm may win the support of scientists by showing a greater adherence to the good-making requirements than was exhibited by their previous beliefs, this cannot be taken by the scientists as evidence that the new paradigm is in any sense objectively 'better'. Lakatos has famously commented that Kuhn's account renders theory-choice 'a matter for mob psychology' ([1970], p. 178).

The consequences for theory-assessment in the historiography of science are radical: if there exist no supra-paradigmatic standards of evaluation, the historian possesses no objective yardstick against which to judge past science. The so plausible undertaking outlined in the previous section is thereby reputed impossible.

\section{COMPREHENSION AND CRITICISM}

Kuhn's arguments for the occurrence of scientific revolutions constitute an obstacle in the path of evaluations of past science different from and greater than those posed by the other strands in modern philosophy considered in the previous section. For whilst historiographic conventionalism or externalism seek merely to demonstrate the undesirability of assessing the truth and rationality of past science, Kuhn maintains that such a programme is no less than impossible: the division of the course of science into periods of normality separated by putative discontinuities of meaning and rationality would render it impossible for us to project our judgement beyond the period and area of hegemony of our current paradigms. Thus the first task for those who would indulge in the assessment of past theories is to establish its very feasibility by undermining Kuhn's scepticism concerning this activity.

Clearly no historiographic activity would be possible given a total failure of translation from past texts as envisaged by Quine; the substantive 
challenge is therefore to secure evaluations of past science in the face of partial failure. This has been attempted by M. B. Hesse ([1973], pp. 146-7) who aims to establish a sense in which the development of science stands outside historical relativity and is absolutely progressive. As she concedes, the relativist has demonstrated that conceptual constructs undergo deep revolutions and do not converge continuously towards the truth: for this reason the progress of science is not a mere increase in the number of true observation statements accounted for in successive theories, since the language of observation is permeated by theory. But there is a sense, Hesse claims, in which science provides us with increasing knowledge, and it is related to technological control. It is undeniable that the contemporary scientist is better able to predict and manipulate phenomena than were his predecessors:

Because this sense of the progress of science is about controlled happenings, it is independent of the way facts are described relative to different theories. [. . . It provides an absolute criterion of distinction of our rationality [ . . ]. (Ibid., p. 147)

Hesse suggests that the resultant continuity provides a basis upon which to ground evaluative judgements of past theories, even across putative paradigm-switches.

This argument does not appear fully persuasive since the continuity which it envisages is merely instrumental: if the sole invariant feature of science were its predictive power, all evaluation of past science open to us would consist exclusively of a numerical tally of its empirical successes and not touch upon issues of the truth-value or rationality of theories, so missing the burden of our enterprise. Hesse here appears to have conceded excessive ground to her opponents. Conversely, relativists like P. Feyerabend would not admit Hesse's premise that there has in history been a monotonic increase in the predictive power of science, stressing on the contrary that past theories scored some successes not replicated by current science, and that prediction is in any case not the sole aim of theories. A different base upon which to ground evaluations of the rationality and truth of past science would in the face of these Kuhnian rebuttals appear desirable: one will be outlined now.

First, the sole way in which to identify a scientific revolution is surely by noticing that our estimation of the canons of rationality employed at around its time changes at the boundary that the putative revolution constitutes. Inferences peculiar to past paradigms will diverge from those that we under the same premises would find legitimate to draw, and given a pair of past paradigms the characteristic inferential patterns that we perceive in each will diverge from ours in different ways. If they did not, and hence there were no visible discontinuity of reason in the period examined, it would make no sense to postulate the occurrence of a revolution. So the transparadigmatic evaluation of rationality is no less than a precondition for the formulation of the concept of radical standard variance if the latter is to refer 


\section{Fames $W$. McAllister}

to identifiable historical junctures. It will no doubt happily be noted by Kuhnians that evaluations performed for this purpose confer no privilege on our own canon of rationality which is therein employed solely as a rational null-indicator to reveal discontinuities that, as Kuhn too claims, would show on any base adopted.

Now to evaluations of truth, to which the challenge posed by radical meaning variance centres on the alleged impossibility of comprehending the more theory-laden terms of past science. The situation here confronting the historian of science is analogous to that which faces a physician attempting to establish the history of a disease from the answers provided by a medically untutored patient. The doctor meets difficulty in comprehending his patient for two reasons: first, some of the latter's terms and expressions may be ambiguous or possess meanings different from those which the doctor would attribute to them in his own technical vocabulary; secondly, the patient's conception of the processes of disease themselves may depart to an unspecified degree from the doctor's understanding of the truth so it is uncertain what the patient is even attempting to describe. A Kuhnian practitioner would thus expect no chance of evaluating the accuracy of his patient's assertions and thus of conferring upon them truth-values. The historian is said to operate under a similar double handicap: he cannot fully understand the scientific text before him which is in any case striving to describe a situation that strays from the real to an indeterminate degree. Under these conditions, proponents of the incommensurability thesis claim that any attribution of truth-value to an outdated theory will be wholly arbitrary since it will rely upon a construal of meanings designed precisely to lead to the verdict desired by the investigator. This charge of circularity will be seen below in reality not to stand. What has given rise to this charge is a methodological principle which has suspect legitimacy but is nonetheless at present generally invoked against meaning variance by those who would carry out evaluations of truth: the principle of charity, that for instance we should assign to past terms those referents which render true the greatest number possible of the propositions in which those terms figure, or that the assigned extensions of past predicates should show the widest possible overlap with the extensions of the corresponding predicates in ourbelieved true-theories. (This principle is quite separate from the so-called 'principle of humanity' which calls for the assignation of referents to past terms in such a way as to optimize the intelligibility of the statements in which they figure.) The principle of charity was first proposed over twentyfive years ago by N. L. Wilson ([1959], p. 532) and is nowadays often regarded as an a priori methodological rule; D. Davidson endorses this claim when he writes that

charity is not an option, but a condition of having a workable theory [...]. Charity is forced on us; whether we like it or not, if we want to understand others, we must count them right in most matters. ([1973], p. 19) 
This procedure of minimizing disagreement is especially visible in the case of terms which are no longer reputed to refer. For example Joseph Priestley believed in the phlogiston-theory because of observations which he described in theory-laden terms such as

When iron is melted in dephlogisticated air, we may suppose that, though part of its phlogiston escapes, to enter into the composition of the small quantity of fixed air which is then procured, yet enough remains to form water with the addition of dephlogisticated air which it has imbibed, so that this calx of iron consists of the intimate union of the pure earth of iron and of water [. . . ]. ([1785], pp. 299-300)

The term 'phlogiston' is now known not to refer and so cannot be learned ostensively: other means are required in order to recover from Priestley's descriptions what this word was intended to denote. By routine charitable construal of the terms 'iron', 'water' and the like as possessing their modern meanings, historians have ascribed to Priestley the greatest possible truthcontent by identifying 'dephlogisticated air' with 'oxygen'. The business of assessing in exactly how much truth this maximum consists is thereafter unproblematic since an unambiguous glossary of the terms of phlogistonchemistry has been constructed. But the major weakness of this approach lies upstream of this point and precisely in the assumption of the principle of charity and that hence the greatest possible truth-content should invariably be read into past texts. Why, when we know how easy it is to assert a gravely incorrect theory? The physician of our example may well under the principle of humanity strive to optimize his comprehension of the patient by assigning an appropriate interpretation to the latter's statements, but will generally not choose to construe as many as possible of them as factually correct, particularly if there are doubts about the sick person's grasp of medical processes: rather will the doctor judge in each case the degree of credence to be lent to the patient's answers by reference to the apparent rationality of the reasoning from which they derived. This hermeneutical procedure should equally be followed in the historiography of science. The principle of charity amounts therein to a withdrawal of autonomy from assessments of truth, which are considered to follow mechanically from a maximization of the truth-content of past scientific writings. But plainly a deliberate decision should be made of the degree of charity to be applied in each case: and such decisions are taken by our prior assessments of rationality. The optimally rational investigator is the one who of all the competitors under equal conditions reaches the most truth; any decrease in his standard of rationality would tend to introduce increasing falsehood into his reports. So it is wrong to present-as Davidson does-the principle of charity as an a priori assumption not admitting of exceptions: our expectations of truth must on the contrary be calibrated against our estimations of the rationality of our subjects of study. (In turn this latter activity is invariably possible as was observed in the previous paragraph.) In the case of the phlogiston-theory we must thus evaluate Priestley's 
rationality in order to gauge just how closely his descriptions will have matched the phenomena before him. Believing him scientifically competent we may construe his descriptions favourably, but if he had been a less discriminating theorist the intended meanings of his terms might have been different from those we would most charitably assume and his arguments for the existence of 'phlogiston'-whatever this term denotedconsequently been less secure. So although our esteem of major named figures in the historical record may be invariably high, it should be viewed as the outcome of no less a deliberate decision for that-a decision to be argued and reached on the basis of evaluations of rationality.

Once reached, the denotations of the terms contained in past theories and the truth-values of the assertions in which they figure may be determined in the same manner as under an acritical principle of charity. But in the light of the above argument those denotations and truth-values are seen to be established on the basis of evaluations of rationality rather than on an arbitrary methodological principle. Such evaluations are thus rooted in the initial search for discontinuities of reason or 'revolutions' which was considered above. True, whilst in that context evaluation conferred no privilege on our beliefs, in this latter connection we openly judge the standard of rationality of past scientists by our lights alone. But this is no defect of the above argument, for two reasons. First, its aim was to counter Kuhn's contention that evaluations of past truth were-owing to radical meaning variance-impossible, and to show that on the contrary such assessments are potentially well-founded: and this it has done. A denial of the incidence of historiographic bias never was among its self-imposed tasks. Secondly, we have been conducting judgements of rationality for purposes of historiography, and a written history is inevitably tainted by the environment of its composition on many grounds other than these, which would thus in any case be swamped.

To summarize: the above arguments have attempted to show that despite Kuhn's assertion of incommensurability it is feasible to perform evaluations of truth in that it is possible to comprehend past scientific terms by assigning to them denotations. In turn this is accomplished with the aid of assessments of rationality, which we have noted are invariably possible-albeit biasedand indeed essential to the secure foundation of Kuhn's thesis itself. Neither as a consequence do evaluations of truth suffer from circularity: they hang not from an arbitrary principle of charity manufactured solely to ensure a certain verdict in those same evaluations, but rather from assessments of a different species - of rationality. Evaluations thus lie not in a circle but in a progression in which both the rationality and the truth of past science may securely be gauged by the historian.

This conclusion is buttressed by the realization that such evaluations have concretely been performed in history by scientists themselves in the many incidents in which scientific theories were at first rejected or neglected and much later revived and accepted as correct. These are cases in which the 
scientific community has overturned its assessment of a theory after a sometimes considerable lapse, pragmatically demonstrating the possibility of projecting such judgements over time. For instance, Christiaan Huygens published in 1690 a wave-theory of light capable of explaining many optical phenomena, including - alone among the available theories-double refraction in calcite. This theory was nonetheless rejected for around a century in favour of the Newtonian approach with which it was inconsistent and revived only in $180 \mathrm{I}$ by Thomas Young. Again, Benjamin Thomson's 1798 vibration-theory of heat was perceived as superior to the competing caloric theory only in the 1840 s by Ludwig Boltzmann. Other examples of theories upon which the judgement of the academic community was changed from unfavourable to positive after a sometimes lengthy interval include $I$. Semmelweis' theory of the cause of puerperal fever of 1847 , M. Polanyi's 1914 theory of adsorption and N. Bohr's 1927 Complementarity Principle. ${ }^{1}$ What matters in such cases is that the scientific community was able to pass evaluations of truth and rationality upon past theories; the test of the wellfoundedness of such evaluations is that in all such cases science was able to build upon these past achievements thus revalued and incorporate them into current beliefs. They consequently provide prima facie instances of the assessment of theories originally formulated in a past time, which counter Kuhn's conclusions to the extent required to establish the possibility of theory-evaluation in historiography.

\section{THE ROLES OF EVALUATION}

The possibility of the evaluation of past theories assured, it remains to suggest its desirability by countering the strands in recent philosophy outlined in section 2 above, which have tended to relativize the historian's criteria of rationality. The issue with which those strands were grappling was that of determining what should count as reasons for beliefs in the historiography of science. In his influential Foundations of Historical Knowledge M. White suggests that when a historian inquires why named historical figures held certain beliefs, he may give a rational explanation in terms of 'the reasons stated by the thinkers or half-stated by them, or the reasons they would have stated if they had been asked certain questions'. ${ }^{2}$ This characterization however leaves ambiguous the status which reasons must possess if they are legitimately to be employed in historiography. It would appear difficult to maintain that reasons are atemporal motivations to which philosophers as such are inevitably subject, for past construals of certain arguments appear notoriously distant from those of present-day

\footnotetext{
${ }^{1}$ See e.g. on Huygens Laudan [1977], pp. 232-3, on Thomson ibid., p. 83, on Semmelweis Sinclair [1909], on Polanyi his own [1 963] and on Bohr Holton [1970].

${ }^{2}$ White [1 965], p. 196. White's views are further analyzed in Hesse cit., pp. 134-9, on which my discussion draws.
} 


\section{8 fames W. McAllister}

thinkers. The Whiggish shortcomings of this perspective would be avoided if we were to give rational explanations of a past belief in terms of what would have been seen as reasons at the time, but this option too meets immediate difficulties. First, it sets historians the task of discovering what reasons truly governed the scientist's beliefs; this is sometimes difficult since such reasons are not always expressed, particularly once the theories concerned have become entrenched, and since even when scientists do lay out their principles explicitly they may be misdescribing their procedures out of lack of awareness or conformity to prevailing intellectual fashion: certain past scientists notoriously departed from their stated methodological tenets in practice. Secondly, no one form of rationality has commanded universal assent in the history of thought: some once fashionable modes of argument have long been discredited and so possess no logical explanatory force on today's standards. It is impossible then to advocate using past arguments to explain past beliefs when faith in the former is to us no less arbitrary and mysterious than credence in the latter. In such cases the arguments employed by past scientists do not today constitute the explanantes of their beliefs but rather must number alongside those same beliefs as the historian's explananda. Copernicus reportedly inferred that the Sun is at the centre of the planetary system from its analogy with a monarch at the centre of his court: we are not convinced by this argument and indeed find it more alien than the conclusion. Copernicus' belief in the latter is thus not to us explained by his faith in the former at least until we have found reasons acceptable to us for the sixteenth-century confidence in analogies between the Solar System and a royal court. In the Renaissance a wide diversity of such accepted patterns of argument transpires, and their historian is then far from being able to presuppose at the outset an adherence to a certain mode of rationality among his subjects of study: on the contrary his task is precisely to determine which forms of inference were then trusted. And although epochs since the Renaissance may appear to exhibit less divergent or rapidly changing conceptions of rationality, the difficulties of principle cast much doubt on the possibility of explaining past beliefs in terms of what would have been seen as reasons at the time.

The option thereby suggested is that of accounting for past beliefs in terms of just what strike us as reasons and only later turning to the separate problem of establishing how far the justifications - suitably reinterpretedactually once given for those beliefs match those that we have attributed to them. This procedure amounts quite simply to the evaluation of past thought, the enterprise discussed above: for we are implicitly allowing the possibility that whilst certain past beliefs will be vindicated by appeal to present reason, others may be found to have been unwarranted. The degree of justification that we attribute to beliefs in history constitutes precisely an assessment of the rationality of their proponents. Two positive arguments in favour of accounting for past beliefs in terms of present-day reasons will be outlined here: the claims that evaluative judgements yield additional 
historical information not easily obtained by other means, and that they are a precondition for the identifying and explaining of scientific progress.

The most convincing support for the first argument is provided by exemplification. One of the main problems facing Galileo in the Discorsi of 1638 was that of motion in a resisting medium: in the Fourth Day he attempted to show that air resistance was independent of velocity by impressing upon one of two identical pendulums oscillations of around $160^{\circ}$ whilst allowing the other to swing through only $10^{\circ}$, noting their behaviour throughout. Galileo tells us that

if the air offers more resistance to the high speed than to the low, the frequency of vibration in the large arcs [. . .] ought to be less than in the smaller arcs [. . . ], but this prediction is not verified by the experiment; because if two persons start to count the vibrations, the one large, the other small, they will not differ by a single vibration, not even a fraction of one. ([1638], p. 244)

Yet in 1976 the historian R. H. Naylor correctly quoted for this experiment a very different result:

Using two similar lead pendulums 100 inches long, I allowed one to swing initially through $120^{\circ}$ and the other through $10^{\circ}$. I found that the pendulums were a quarter of an oscillation out of step after eight or nine vibrations. Thus Galileo's description of this particular experiment does not agree with the actual case at all. ([1976], pp. 400-1)

It is upon the blatantly evaluative last sentence of this passage and others that commentators have pinned their fruitful construal of many Galilean experiments as didactic thought-demonstrations manufactured for their persuasive power after the completion of the relevant theory rather than as true sources for Galileo of raw data. Our replication of this historical mechanism has led us to opinions of our own on the text's veracity and thence to a new interpretation of the role of experimental evidence in Galileo. An evaluation of past science has here visibly provided the basis for much of the current literature on a major figure of the scientific revolution.

Similarly, Aristotle appears generally to have been a very accurate biological observer and dissector; ${ }^{1}$ when his anatomies diverge too grossly from the organisms as we know them from our observations, the historian is thereby led to suspect that Aristotle is not relating his own findings but may be drawing upon metaphysical beliefs or reporting the results of others: these suggestions are historically revealing. For instance, we know that certain of the corporeal differences which Aristotle claimed to have noted between men and women do not exist; that Aristotle contrary to observational evidence believed they did may inform us of social attitudes prevalent at his time, provided we are prepared to exploit our own evaluations of the truth of Aristotelian writings. Again, explicit epistemologies in the early nineteenth century in Britain were mainly

${ }^{1}$ This example and the next were suggested to me by Hull [1 979], p. 13 and p. 10 respectively. 
inductivist; on this basis many alleged that the Darwinian theory of evolution was unscientific because the product of hypothesis. The historian is able to go far beyond a mere description of this controversy by noting that Darwin's methods e.g. in his Notebooks on Transmutation admittedly departed from the inductivist precepts of John Stuart Mill but no more than did the procedures of other nineteenth-century scientists: this evaluation reveals the fact that the methods suggested by Mill and others were not embodied in current science and hence that their advocates' criticism of Darwin was not biting. This new information is owed precisely to evaluative judgements. Lastly, the most salient problem recently to emerge from the study of Oriental science is that of explaining why, although China until about 1400 was scientifically and technologically more advanced than Europe, the scientific culture developed by the West in the succeeding three centuries was signally unmatched there. The explanation advanced by $J$. Needham refers to the centralized control of technological development by the mandarinate and to the Chinese bourgeoisie's impotence to bridge the gap between intellectual and manual labour; whatever the correct explanation, the possibility of even posing this fruitful question depends upon the belief that past states of science can be normatively compared.

The above examples have illustrated the range of historiographic problems and explanations access to which is unobtainable without assessment of past science and have clearly demonstrated the prize that would be lost if such evaluations were banned. But perhaps the more powerful argument in favour of the assessment of past theories is that they are necessary for the recognition and explanation of scientific progress. ${ }^{1}$ Few thinkers in current philosophy doubt the manifestation of some form of progress in science: K. R. Popper, Lakatos and Laudan may differ in their conception of progress and their theories about its features, but do not disagree about its occurrence; even Kuhn does not question this. Progress also forms the basis for debates on realism, a common argument for which is that without the realist assumption that there is some convergence of scientific theories towards the truth, the success of science in correctly predicting observable phenomena would be a miracle. Thus any test of this assumption involves the detection of progress, and in turn the recognition and explanation of progress requires the differential assessment of beliefs.

First, in referring to progress we are characterizing the beliefs of later scientists as containing more truth than did those of their predecessors. We are not merely reporting their own perception of their achievement but also concurring in this judgement. So we require our own evaluations of past efforts in order to recognize the occurrence of progress. Its explanation too possesses this requirement: theory-change can be explained by reconstructions of lines of reasoning without assessing beliefs, but if an explanation is desired of why this transition constituted progress, reference must be made

\footnotetext{
1 This argument is presented in Newton-Smith [1981], ch. 10, on which 1 have drawn.
} 
to the truth-content of the theories involved. If we wish to explain past transitions we can do so by showing that the participants were acting reasonably by their own standards: such explanations do not require us to endorse their beliefs. However, if we want to explain why there was progress and not merely change we shall need to attribute truth-values to their beliefs: the latter activity plainly involves evaluation whereas the former does not. Lastly in the explanation of progress the historian will wish to eliminate the possibility that science has so far been the product of lucky accidents by showing that the reasons of past eras (if necessary interpreted into modern terms) partly coincide with or approximate to our own, and perhaps show an ordered evolution in scientists' conception of reasons for beliefs. Nonetheless progress cannot to us be explained by past canons of rationality except precisely in so far as the latter may be identified with our own.

To illustrate the difference between explanation of theory-change alone and of progress we may take the Principia Mathematica, of which Newton claims that the method is inductive, proceeding by generalizations from singular observations. He presents the axiomatic section which opens the Principia as resting on inductive evidence of precisely this kind: the implication is that each of his three laws of motion is based on an inductive generalization from observed instances of the operation of forces and masses. The empiricism and anti-hypotheticalism of this construal was a major attraction of the Principia in England and so can explain the belieftransitions of many who embraced Newton's mechanics; but it does not, particularly in the light of debates on induction from Hume to the present day, explain why Newtonianism was more successful than and hence constituted progress over its predecessors. To explain this, the historian lays aside the author's protestations and notes that the three laws are not inductive but rather conjectural, depending in a crucial way upon the introduction of new and complex explanatory terms, 'force' and 'mass', which are defined within the axiomatic structure and to which classical mechanics owes its predictive success. Now there is no suggestion that it was this hypothetico-deductive structure that attracted empiricists to Newton: they would more likely have objected to the Principia if they had seen it thus. But what this construal does purport to explain is why Newton's mechanics was successful as science and why it has been a progressive contribution to physics. And to establish this construal we have had to resort to our evaluation of Newton's methodological claims and to our own judgement, guided by normative hindsight, of the structure of the Principia.

Therefore to identify and explain progress and thereby inter alia to permit investigation of convergent realist arguments, it is necessary to develop a normative model of theory-appraisal and to show that the community of scientists have made decisions with results that approximated to it in some degree. Recognition of this point and of the impact of the previously outlined arguments suggests that the evaluation of the truth and rationality 


\section{James $W$. McAllister}

of past science not only is an essential component of the written history of science but also has a positive role for epistemological speculation. In particular the debate which provided the original motivation for this enterprise-the discussion between Lakatos, Laudan and others on the evidential role of history for philosophy - has been given a sound base: since assessments of past theories are in principle well-founded, the evaluated rationality of historical episodes may after all be brought sensibly to bear as evidence to adjudicate between competing methodologies.

If these claims are accepted, not just the possibility but also the desirability of such evaluations has been established. In this light it would be surely counterproductive to propose the eradication from historiography of the exercise of normative judgement. The critical faculties that we so enjoyably direct against our contemporaries are profitably trained onto our scientific predecessors also.

fesus College, Cambridge

\section{REFERENCES}

AGASSI, J. [1962]: 'Towards an Historiography of Science', History and Theory, 2, Beiheft 2, pp. I-1 17 .

BACHELARD, G. [1934]: Le nouvel esprit scientifique. Presses Universitaires de France (1973).

BARNES, B. [1977]: Interests and the Growth of Knowledge. Routledge and Kegan Paul.

Brown, J. R. [1 980]: 'History and the Norms of Science', in P. D. AsQuiTH and R. N. Giere (eds), PSA r98o, vol. I. Philosophy of Science Association (1980). Pp. 236-48.

BruSH, S. G. [1974]: 'Should the History of Science be Rated X?', Science, 183, pp. I $164-72$. BUTTERFIELD, H. [1931]: The Whig Interpretation of History. Bell.

Clagett, M. (ed.) [1959]: Critical Problems in the History of Science. University of Wisconsin Press.

Clark, J. T. [1959]: 'The Philosophy of Science and the History of Science', in M. ClaGeTT (ed.) [1959], pp. 103-40.

Davidson, D. [1973]: 'On the Very Idea of a Conceptual Scheme', Proceedings of the American Philosophical Society, 47, pp. 5-20.

FLECK, L. [1935]: Genesis and Development of a Scientific Fact. Translated by F. BRADLEY and T. J. Trenn. University of Chicago Press (1979).

GaliLeI, G. [1638]: Dialogues Concerning Two Newo Sciences. Translated by H. CREW and A. DE SALvio. McGraw-Hill (1963).

Glanvill, J. [1668]: Plus Ultra: Or the Progress and Advancement of Knowledge. J. Collins.

Hesse, M. B. [1973]: 'Reasons and Evaluation in the History of Science', in M. TEICH and R. Young (eds), Changing Perspectives in the History of Science. Heinemann. Pp. 127-47.

HoLtoN, G. [1970]: 'The Roots of Complementarity', Daedalus, 99, pp. 101 5-55. Reprinted in G. Holton, Thematic Origins of Scientific Thought. Harvard University Press (1973). Pp. II 5-61.

Howson, C. (ed.) [1976]: Method and Appraisal in the Physical Sciences. Cambridge University Press.

HuLL, D. L. [1979]: 'In Defense of Presentism', History and Theory, 18, pp. 1-1 5.

KuHN, T.S. [1962]: The Structure of Scientific Revolutions. Second edition 1970. University of Chicago Press.

Kunn, T. S. [1977]: The Essential Tension. University of Chicago Press.

LAKATOS, I. [1970]: 'Falsification and the Methodology of Scientific Research Programmes', in I. LAKatos and A. Musgrave (eds), Criticism and the Growth of Knowledge. Cambridge University Press. Pp. $91-196$.

LAKATOS, I. [1971]: 'History of Science and its Rational Reconstruction', in R. C. BUCK and 
R. S. CoHen (eds), Boston Studies in the Philosophy of Science, vol. 8. Reidel. Reprinted in C. Howson (ed.) [1976], pp. I-39.

Laudan, L. [1977]: Progress and Its Problems. University of California Press.

NAGEL, E. [1959]: 'Commentary on the Papers of A. C. Crombie and J. T. Clark', in M. ClaGeTt (ed.) [1959], pp. 153-61.

NAYLOR, R. H. [1976]: 'Galileo: Real Experiment and Didactic Demonstration', Isis, 67, pp. 398-4I9.

Newton-Smith, W. H. [1981]: The Rationality of Science. Routledge and Kegan Paul.

Polanyi, M. [1963]: 'The Potential Theory of Adsorption: Authority in Science has its Uses and its Dangers', Science, 141, pp. 1010 3.

Priestley, [1785]: 'Experiments and Observations Relating to Air and Water', Philosophical Transactions of the Royal Society, 75, pp. 279-309.

QUine, W. V. [1960]: Word and Object. M.I.T. Press.

SinCLAIR, W. J. [1909]: Semmelweis: His Life and His Doctrine. Manchester University Press. WHITE, M. [1965]: Foundations of Historical Knowledge. Harper and Row.

Williams, L. P. [1975]: 'Should Philosophers be Allowed to Write History?', British fournal for the Philosophy of Science, 26, pp. 241-53.

WiLSON, N. L. [1959]: 'Substances without Substrata', Review of Metaphysics, 12, pp. 52 1-39. 